\title{
Spinal Cord Neoplasm
}

National Cancer Institute

\section{Source}

National Cancer Institute. Spinal Cord Neoplasm. NCI Thesaurus. Code C3381.

A primary or metastatic neoplasm affecting the spinal cord. 